\title{
Impact of COVID-19 on the Mental Health of Healthcare Professionals in Pakistan
}

Ram Sandesh $^{1}$, Wajeeha Shahid ${ }^{2}$, Kapeel Dev ${ }^{3}$, Nikeeta Mandhan ${ }^{4}$, Prem Shankar ${ }^{5}$, Anam Shaikh ${ }^{6}$, Amber Rizwan ${ }^{7}$

1. Medicine, Liaquat University of Medical and Health Sciences, Jamshoro, PAK 2. Internal Medicine, Jinnah Sindh Medical University, Karachi, PAK 3. Internal Medicine, Ghulam Muhammad Mahar Medical College, Sukkur, PAK 4. Internal Medicine, Dr. Ruth K. M. Pfau Civil Hospital, Karachi, PAK 5. Internal Medicine, Dow Medical College, Karachi, PAK 6. Internal Medicine, Dow University of Health Sciences, Karachi, PAK 7. Family Medicine, Dr. Ruth Pfau Hospital, Karachi, PAK

Corresponding author: Amber Rizwan, amber_aljazeera109@hotmail.com

\section{Abstract \\ Introduction}

As a result of the ongoing COVID-19 pandemic, health care professionals (HDPs) are facing immense strain due to the heavy load of cases. In many cases, they work increasingly long hours, often with limited resources and a dubious infrastructure. Thus, it is important to check on the mental health of caregivers.

\section{Methods and materials}

This cross-sectional study was conducted in May 2020, at various hospitals in Karachi, Pakistan. All HCPs posted in the COVID-19 isolation wards were invited to participate and a total of 112 completed this study. A carefully structured form was created, which included the Depression Anxiety Stress Scale-21 (DASS-21).

\section{Results}

The overall mean score of anxiety was $19.01 \pm 9.2$, depression was $18.12 \pm 10$, and stress was $20.12 \pm 12.0$. There were 81 (72.3\%) participants who suffered from moderate to extremely severe depression, 96 ( $85.7 \%$ ) participants who suffered from moderate to extremely severe anxiety, and 101 (90.1\%) participants who reported moderate to extreme stress levels

\section{Conclusions}

It is evident that there are a high number of healthcare workers affected by various psychological ailments such as anxiety, stress, and depression. It is important that the government take steps to ensure that HCPs' mental health is regularly checked and that efforts are made to reduce their burdens.

Received 06/18/2020

Review began 06/28/2020 Review ended 06/28/2020 Published 07/02/2020

(c) Copyright 2020 Sandesh et al. This is an open access article distributed under the terms of the Creative Commons Attribution License CC-BY 4.0., which permits unrestricted use, distribution, and reproduction in any medium, provided the original author and source are credited.
Categories: Preventive Medicine, Psychiatry, Infectious Disease

Keywords: covid 19, pakistan, mental health

\section{Introduction}

COVID-19, also known as coronavirus disease, was first identified in Wuhan, China, in late 2019. It is a highly contagious disease with a rapidly rising incidence globally. The World Health Organisation (WHO) recognized it as a pandemic due to its widespread transmission [1]. As is the standard procedure in such pandemics, a lockdown is usually enforced to limit the spread of the disease and reduce potentially new cases by maintaining social distancing in all public places [2]. The general public undertakes such safety measures, but health care professionals (HCPs) are unfortunately left exposed to deal with the many issues that arise due to this situation. Firstly, due to a huge load of cases as a result of the pandemic, health care professionals face increasingly long work hours, often with limited resources and a dubious infrastructure [3]. Secondly, they face physical discomfort and sometimes even breathing difficulties while wearing personal protective equipment (PPE), which is essential to keep them safe from exposure to the virus [4]. Another big problem faced by the HCPs is that because little is known about the new virus/disease, and therefore, no established protocols or evidence-based clinical treatments are prevalent, many HCPs feel unprepared to carry out their duties [4]. And then there is a very valid fear of autoinoculation and the risk of spreading the virus to their family and friends [5-6]. This fear leads HCPs to isolate themselves from their families, alter their daily routines, and even reduce their social support system, all in the hopes of keeping everybody potentially safe from themselves [4].

Unsurprisingly, all these factors take a toll on the mental health of HCPs. In 2003, during the outbreak of severe acute respiratory syndrome (SARS), $18-57 \%$ of HCPs suffered severe emotional problems and psychiatric symptoms both during and after the breakout [7]. In 2015, when the Middle East respiratory 


\section{Cureus}

syndrome (MERS) emerged, also caused by a coronavirus, HCPs suffered dysphoria and stress [7]. Many other studies have reported that mental health implications for professionals involved in healthcare during epidemics and pandemics are long-lasting. Even after some time had transpired after such events, high levels of stress, anxiety, depression, and even post-traumatic stress disorder (PTSD) were observed in many cases $[8-9]$.

Therefore, it is extremely important to identify the HCPs who are at high risk of burnout and are more likely to suffer from anxiety, depression and stress in this pandemic, so that help can be provided where and when needed. It is also equally important to identify and address the factors responsible for this stress. In this study, we will establish the frequency of HCPs affected by anxiety, depression, and stress, as well as determine the causative factors behind them.

\section{Materials And Methods}

This cross-sectional study was conducted in May 2020, at various hospitals of Karachi, Pakistan. All health care professionals (HCPs) posted in the isolation wards for COVID-19 were invited to participate. A total of 112 HCPs completed this study. A carefully structured form was created, which included the English version of the Depression Anxiety Stress Scale - 21 (DASS-21). DASS-21 is a 21-item self-report validated tool designed to measure the three related negative emotional states, which are: depression, anxiety, and stress [10]. The online form also included various reasons that HCPs thought were predisposing factors for anxiety, stress, and depression. The participants could choose multiple reasons as applicable to themselves. The collected data were analyzed using SPSS Version 21.0 (IBM Corp, Armonk, NJ). Mean and standard deviation (SD) were calculated for the scores of anxiety, stress, and depression. Frequencies and percentages were calculated for the severity of DASS-21 and reasons predisposing healthcare professionals to anxiety, stress, and depression.

\section{Results}

Out of the 112 health care professionals (HCPs) who participated in this study, 64 (57.1\%) were male, and 48 (42.9\%) were female. The overall mean score of anxiety was $19.01 \pm 9.2$, depression was $18.12 \pm 10$, and stress was $20.12 \pm 12.0$. There were 81 (72.3\%) participants who suffered from moderate to extremely severe depression, 96 ( $85.7 \%$ ) participants who suffered from moderate to extremely severe anxiety, and 101 (90.1\%) participants who reported moderate to extreme stress levels (Table 1).

\begin{tabular}{|c|c|c|c|c|c|c|}
\hline \multirow{2}{*}{ DASS-21 } & \multicolumn{2}{|l|}{ Depression } & \multicolumn{2}{|l|}{ Anxiety } & \multicolumn{2}{|l|}{ Stress } \\
\hline & Male $(n=64)$ & Female $(n=48)$ & Male $(n=64)$ & Female (n=48) & Male $(n=64)$ & Female $(n=48)$ \\
\hline Normal & $6(9.3 \%)$ & $5(10.4 \%)$ & 0 & $5(10.4 \%)$ & $2(3.1 \%)$ & $2(4.1 \%)$ \\
\hline Mild & $8(12.5 \%)$ & $12(25 \%)$ & $3(4.6 \%)$ & $8(16.6 \%)$ & $4(6.2 \%)$ & $3(6.2 \%)$ \\
\hline Moderate & $16(25 \%)$ & 7 (14.5\%) & $15(23.4 \%)$ & $10(20.8 \%)$ & $16(25 \%)$ & $13(27 \%)$ \\
\hline Severe & 25 (39\%) & 20 (41.6\%) & 32 (50\%) & 17 (35.4\%) & 29 (45.3\%) & 22 (45.8\%) \\
\hline Extremely Severe & $9(14 \%)$ & 4 (8.3\%) & $14(21.8 \%)$ & $8(16.6 \%)$ & $13(20.3 \%)$ & $8(16.6 \%)$ \\
\hline
\end{tabular}

TABLE 1: Frequency of Anxiety, Depression and Stress among Health Care Providers

Abbreviations, DASS-21: Depression Anxiety Stress Scale

The study found that the most common reason for stress and anxiety among HCPs treating COVID-19 positive patients was the fear that they might infect their family members (89.2\%), followed by the fear of getting infected themselves (80.3\%). Other reasons were: increased workload (64.2\%), lack of PPE (62.5\%), lack of security (62.5\%), and lack of awareness among the general population about COVID-19 (46.4\%) (Table 2). 


\section{Cureus}

\begin{tabular}{|c|c|c|}
\hline Reasons & Male $(n=64)$ & Female $(n=48)$ \\
\hline Possibility of contracting COVID-19 & $51(79.6 \%)$ & $39(81.2 \%)$ \\
\hline Possibility of infecting their family & $59(92.2 \%)$ & $41(85.4 \%)$ \\
\hline Lack of PPE & $42(65.6 \%)$ & $28(58.3 \%)$ \\
\hline Lack of security & $41(64 \%)$ & $29(60.4 \%)$ \\
\hline Increased workload & $41(64 \%)$ & $31(64.5 \%)$ \\
\hline Lack of awareness among general population & $30(46.8 \%)$ & $22(45.8 \%)$ \\
\hline
\end{tabular}

TABLE 2: Reasons for Stress, Anxiety and Depression among Health Care Providers

Abbreviations, PPE: Personal Protection Equipments

\section{Discussion}

The psychological response of HCPs to an epidemic could be dependent on many factors which may cause anxiety and stress such as feeling vulnerable to infection, lack of control over the situation, the spread of the virus, health of their family, and being isolated [11]. Other factors may also contribute to stress and anxiety among HCPs such as shortage of PPEs, medicines, etc. and an increasing number of actual and suspected cases [12]. These factors may contribute to various levels and severity of psychological pressure, which may lead to a feeling of loneliness and helplessness and may result in stress, anxiety, irritability, mental fatigue, and depression [4].

In this study, a significant number of Pakistani participants had anxiety, stress, and depression. Around 89\% of HCPs were afraid for their family, and $80 \%$ of HCPs feared that they might get COVID-19 themselves. These figures can be compared to Wuhan, where among HCPs looking after COVID-19 patients, only 50.4\% had depression, $44.6 \%$ had anxiety, $34 \%$ had insomnia, and a considerable proportion of participants had symptoms of depression (634 [50.4\%]), anxiety (560 [44.6\%]), insomnia (427 [34.0\%]), and distress (899 [71.5\%]) [13].

Factors such as improper infrastructure for patient care, lack of awareness among the masses, and poor compliance with safety measures can be accredited to this high prevalence of anxiety, depression, and stress in Pakistan. Another important thing to note is the persistence of mental health implications for healthcare workers. Even after some time had passed after an epidemic, many studies reported that high levels of anxiety, depression, stress, and even PTSD were observed in many HCPs [8].

In addition, the HCPs who are directly involved in the treatment of a highly contagious disease such as the COVID-19 may suffer a stigma whereas, at the other end of the spectrum, this pandemic has led to HCPs being given the 'superhero' status. On the one hand, this adds value and gratification to the job, but on the other, it puts more pressure on the workers, leaving no margin for error. Due to the sensational character of this worldwide pandemic, the 'superhero' status is being reinforced by the media, promoting the need for emotional support, encouragement, and appreciation [14].

In light of the results of this study, it is clear that an alarmingly high number of healthcare workers are the victims of mental health ill-effects caused by the COVID-19 pandemic. It can be also seen that many of the factors due to which HCPs suffer from these ill-effects can be potentially modified, for example, such as free provision of PPEs to all healthcare workers, promoting general public awareness about COVID-19, and building better infrastructure to encourage lighter work hours can all be carried out by the government and thus have a positive impact on the mental health of HCPs.

\section{Conclusions}

In our study, high levels of anxiety, stress and depression among health care professionals were noted, which is a cause for concern. Both the government and health care agencies are responsible for protecting the psychological well-being of health care communities all over the world and ensuring a healthy work environment. Since there is a high prevalence of anxiety, depression, and stress among HCPs treating COVID-19 patients, it is imperative to invest resources to promote the mental health welfare of frontline professionals.

\section{Additional Information}




\section{Disclosures}

Human subjects: Consent was obtained by all participants in this study. Civil Hospital, Karachi issued approval $\mathrm{CH} / 20 / 04 \mathrm{~A}$. Animal subjects: All authors have confirmed that this study did not involve animal subjects or tissue. Conflicts of interest: In compliance with the ICMJE uniform disclosure form, all authors declare the following: Payment/services info: All authors have declared that no financial support was received from any organization for the submitted work. Financial relationships: All authors have declared that they have no financial relationships at present or within the previous three years with any organizations that might have an interest in the submitted work. Other relationships: All authors have declared that there are no other relationships or activities that could appear to have influenced the submitted work.

\section{References}

1. World Health Organization. Novel coronavirus (2019-nCoV) situation reports . (2020). Accessed: July 3, 2020: https://www.who.int/docs/default-source/coronaviruse/situation-reports/20200607-covid-19-sitrep139.pdf?sfvrsn=79dc6d....

2. Wilder-Smith A, Freedman DO: Isolation, quarantine, social distancing and community containment: pivotal role for old-style public health measures in the novel coronavirus (2019-nCoV) outbreak. J Travel Med. 2020, 27 :taaa020. 10.1093/jtm/taaa020

3. Shigemura J, Ursano RJ, Morganstein JC, Kurosawa M, Benedek DM: Public responses to the novel 2019 coronavirus (2019-nCoV) in Japan: mental health consequences and target populations. Psychiatry Clin Neurosci. 2020, 74:281-282. 10.1111/pcn.12988

4. Huang JZ, Han MF, Luo TD, Ren AK, Zhou XP: Mental health survey of 230 medical staff in a tertiary infectious disease hospital for COVID-19 [article in Chinese]. Zhonghua Lao Dong Wei Sheng Zhi Ye Bing Za Zhi. 2020, 38:192-195. 10.3760/cma.j.cn121094-20200219-00063

5. Kang L, Li Y, Hu S, et al.: The mental health of medical workers in Wuhan, China dealing with the 2019 novel coronavirus. Lancet Psychiatry. 2020, 7:14. 10.1016/S2215-0366(20)30047-X

6. Xiang YT, Yang Y, Li W, Zhang L, Zhang Q, Cheung T, Ng CH: Timely mental health care for the 2019 novel coronavirus outbreak is urgently needed. Lancet Psychiatry. 2020, 7:228-229. 10.1016/S22150366(20)30046-8

7. Lee SM, Kang WS, Cho AR, Kim T, Park JK: Psychological impact of the 2015 MERS outbreak on hospital workers and quarantined hemodialysis patients. Compr Psychiatry. 2018, 87:123-127. 10.1016/j.comppsych.2018.10.003

8. Li Z, Ge J, Yang M, et al.: Vicarious traumatisation in the general public, members, and non-members of medical teams aiding in COVID-19 control. Brain Behav Immun. 2020, 1591:30309-3. 10.1016/j.bbi.2020.03.007

9. Ornell F, Schuch JB, Sordi AO, Kessler FH: "Pandemic fear" and COVID- 19: mental health burden and strategies. Braz J Psychiatry. 2020, 42:232-235. 10.1590/1516-4446-2020-0008

10. Arab M, Rafiei H, Safarizadeh MH, Ahmadi JS, Safarizadeh MM: Stress, anxiety and depression among medical university students and its relationship with their level of happiness. IOSR-JNHS. 2016, 5:44-47. 10.9790/1959-05164447

11. Wong TW, Yau JK, Chan CL, et al.: The psychological impact of severe acute respiratory syndrome outbreak on healthcare workers in emergency departments and how they cope. Eur J Emerg Med. 2005, 12:13-18. 10.1097/00063110-200502000-00005

12. Chan-Yeung M: Severe acute respiratory syndrome (SARS) and healthcare workers . Int J Occup Environ Health. 2004, 10:421-427. 10.1179/oeh.2004.10.4.421

13. Lai J, Ma S, Wang Y, et al.: Factors associated with mental health outcomes among health care workers exposed to coronavirus disease 2019. JAMA Netw Open. 2020, 3:e203976. 10.1001/jamanetworkopen.2020.3976

14. Associação de Medicina Intensiva Brasileira. Recomendações para o bem-estar emocional da equipe multidisciplinar durante a pandemia pelo Sars-Cov-2 [text in Portuguese]. (2020). Accessed: July 2, 2020: https://www.amib.org.br/fileadmin/user_upload/amib/2020/marco/18/corona_psico_amib_15h56_18032020.pdf. 